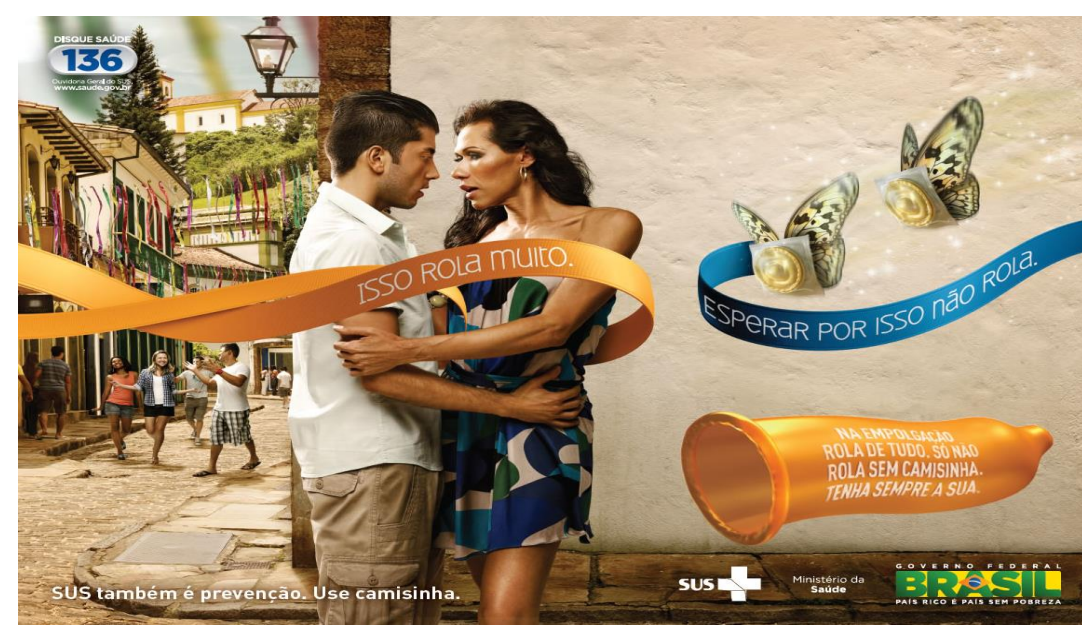

\title{
Sentidos (tra)vestidos: \\ a individuação e a constituição do sujeito travesti pelo Estado ${ }^{1}$
}

Sensen (tra)dresses:

the individuation and the constitution of the transvestite subject by the State

\author{
Lidia Noronha Pereira ${ }^{2}$ \\ Telma Domingues Da Silva ${ }^{3}$
}

\begin{abstract}
Resumo: Filiados ao campo teórico da Análise de Discurso, procuramos discutir nesse trabalho como o sujeito travesti é significado e individuado pelo Estado no Brasil. Portanto, analisamos dois cartazes confeccionados e distribuídos pelo Ministério da Saúde, que compõem a campanha de combate à AIDS. Nosso objetivo foi compreender como o sujeito travesti é discursivamente inscrito em tais cartazes, de circulação nacional e pública, marcados por um gesto administrativo. Os logotipos de esferas de governo que compõem os cartazes demarcam um território, ou seja, um espaço histórico, simbólico e geograficamente institucionalizado. Além disso, nessa posição do Estado, o sujeito travesti é significado de uma certa maneira, uma vez que é convocado por esta campanha também de uma certa maneira. A fim de prosseguirmos com essa análise, foi considerado o corpo do sujeito travesti enquanto forma material (Orlandi, 2012), reconhecendo a sua inscrição no simbólico e que esta inscrição é sustentada pelos discursos específicos. De acordo com nosso ponto de vista, não poderíamos lidar com os cartazes como se eles meramente representaram imagens impressas em formato cartaz. Ao contrário, a nossa análise permitiu apontar efeitos de sentido produzidos para o corpo travesti por um gesto interpretativo, e que esses efeitos significam processos de identificação do sujeito travesti. Há, além disso, os resultados dessa análise que apontam para a necessidade de romper o "já-dito" em relação ao sujeito travesti.

Palavras-chave: Individuação; Estado; sujeito travesti; cartaz; saúde pública.
\end{abstract}

Abstract: Affiliated to the theoretical field of Discourse Analysis, in this work we aimed at discussing how the transvestite subject is signified and individuated by the State in Brazil. Therefore, we have analyzed two posters produced and distributed by the Ministry of Health that compose a campaign to combat AIDS. Our objective was to understand how the transvestite subject is discursively inscribed in such posters of national and public circulation that are marked by an administrative gesture. The logotypes of government spheres that compose the posters demarcates a territory, that is, a historical space both symbolically and geographically institutionalized. Moreover, within that position of the State, the transvestite subject is signified in a certain way as it is convoked by this campaign also in a certain way. In order to proceed with this analysis we considered the body of the transvestite subject a material form (Orlandi, 2012), recognizing its inscription in the symbolic and that this inscription is sustained by specific discourses. According to our perspective, we could not deal with the posters as if they merely represented printed images in poster format. On the contrary, our analysis allowed us to point out effects of meaning produced for the transvestite body by an interpretative gesture, and that those effects signify identification processes for the transvestite subject. There withal, the results of this analysis that point to the necessity of breaking off the "already-said" regarding the transvestite subject.

Keywords: individuation, State; transvestite subject; poster; public health.

\footnotetext{
${ }^{1}$ Apoio: Fundação de Amparo à Pesquisa do Estado de Minas Gerais - FAPEMIG

${ }^{2}$ Doutoranda em Ciências da Linguagem da UNIVÁS. Av. Pref. Tuany Toledo, 470 - 37550-000 - Pouso Alegre MG. E-mail: lidiacambuca2003@yahoo.com.br.

${ }^{3}$ Professora do PPGCL da UNIVÁS. Av. Pref. Tuany Toledo, 470 - 37550-000 - Pouso Alegre - MG. E-mail: telmadds@gmail.com
} 
"Prazer em exercer um poder que questiona, fiscaliza, espreita, espia, investiga, apalpa, revela; e, por outro lado, prazer que se abrasa por ter que escapar a esse poder, fugirlhe, enganá-lo ou travesti-lo. Poder que se deixa invadir pelo prazer que persegue e, diante dele, poder que se afirma no prazer de mostrar-se, de escandalizar ou de resistir."

Michel Foucault

O presente trabalho desenvolve-se a partir do referencial teórico da Análise de Discurso, através de trabalhos de Pêcheux (1969) e Orlandi (2004, 2012). Também procuramos, para a compreensão da questão aqui concernida, dialogar com trabalhos na área da filosofia (por exemplo, FOUCAULT, 1988) e da psicanálise (POLI, 2007). Nosso objetivo é refletir sobre a significação social de um determinado sujeito, considerando-se o funcionamento da linguagem enquanto discurso na sociedade e, associado a este, o efeito do Estado, enquanto articulador simbólico, que se exerce através de suas instituições.

Nesse sentido, questionamos o modo como o travesti se significa e como um certo lugar social está já posto para esse sujeito através da interlocução do Estado com o seu cidadão - o que, no caso, se dá a partir de dois cartazes confeccionados e distribuídos pelo Ministério da Saúde.

Sobre a relação de um determinado sujeito hoje com o Estado, Orlandi (2011) assim descreve o que chama de processo de "individuação":

[...] usamos a palavra "individuação" que remete necessariamente ao fato de que se trata de um sujeito individuado, ou seja, a forma sujeito histórica, no nosso caso capitalista, passando pelo processo de articulação simbólicopolítica do Estado, pelas instituições e discursos, resultando em um indivíduo que, pelo processo de identificação face às formações discursivas, identificase em uma (ou mais) posição-sujeito na sociedade. N.R. (p. 22).

Dessa forma, propõe-se dois movimentos (diferentes, mas não separáveis) no sentido de uma abordagem teórica para se compreender a constituição do sujeito: no primeiro, tem-se a interpelação do indivíduo em sujeito, pela ideologia, no simbólico, resultando na forma-sujeito-histórica; no segundo, tem-se a constituição desta formasujeito-histórica, considerada como modo de individuação do sujeito. Partindo da con- 
cepção de forma sujeito, conforme compreendida, por exemplo, por Haroche (1992), Orlandi afirma a noção de sujeito individuado como política e não psicológica:

[...] As formas de individuação do sujeito pelo Estado, estabelecidas pelas instituições, resultam em um indivíduo ao mesmo tempo responsável e dono de sua vontade. É o sujeito individuado, de natureza sócio-histórica ideológica, indivíduo já afetado pela língua e pela ideologia que se identifica pela sua inscrição nas diferentes formações discursivas, de que resultam distintas posições sujeitos, relativamente às formações sociais. Assim, a noção de sujeito individuado não é psicológica mas política, ou seja, a relação indivíduosociedade é uma relação política. Nesta teorização, nenhum dos elementos que a constituem pode ser pensado sem os demais (p. 22).

Assim, consideramos os cartazes do Ministério da Saúde no Brasil direcionados ao sujeito travesti como gesto de memória de um Estado, gesto que se dá através de um discurso que individua, identifica o sujeito a determinada(s) posição(ções)-sujeito na sociedade.

Observa-se que, no processo de interlocução do Estado com o sujeito travesti, funciona a projeção de um imaginário, conforme descreveu Pêcheux (1969). Pensando em um diálogo entre um sujeito A e um sujeito B, o autor afirma que se deve considerar o lugar social de cada sujeito no discurso. Tais lugares sociais estão representados nos processos discursivos, fazendo funcionar uma série de formações imaginárias que marcam o lugar de A e B, ou, mais especificamente, a imagem que A e B se atribuem um ao outro, a imagem que fazem de seu lugar e do lugar do outro. Sintetizando, Pêcheux afirmará que

existem nos mecanismos de qualquer formação social regras de projeção que estabelecem as relações entre as situações (obviamente definíveis) e as posições (representações dessas situações)" (p. 81-82).

Acrescenta ainda que também o "referente", ou seja, o contexto, a situação do discurso, é pertencente da mesma maneira às condições de produção e passível dessa mesma projeção imaginária. Dessa forma, aponta que

todo processo discursivo supunha, por parte do emissor, uma antecipação das representações do receptor, sobre a qual se funda a estratégia do discurso (p. 83).

Tanto essa reflexão inicial da Análise de Discurso, com a qual Pêcheux deslocase da visão comunicacional nas trocas linguísticas, quanto a noção de individuação conforme proposta por Orlandi são elementos importantes neste trabalho para compreender o funcionamento de um discurso por parte do Estado brasileiro a uma parcela da sua população que é evocada (e convocada) através de cartazes do Ministério da Saúde. 
Assim, consideraremos inicialmente as condições de produção desse discurso médico de Estado, os lugares sociais dos sujeitos envolvidos nesse discurso, bem como as relações de força e o processo de antecipação - inerentes a qualquer funcionamento discursivo.

Importante frisar que a imagem do corpo do sujeito travesti é aqui concebida como materialidade significante: sua inscrição no simbólico e os discursos que a atravessam - não apenas uma imagem impressa em formato cartaz, mas os sentidos para o gesto de interpretação do corpo que vão significar nos processos de identificação do sujeito travesti. Assim, pretendemos analisar como o sujeito travesti é inscrito, pela sua simbolização, em dois cartazes de circulação pública, de âmbito nacional, material que é produto do gesto administrativo do Estado sobre o seu cidadão.

Esse modelo de mídia - o "cartaz" -, utilizado por diversas instituições, busca informar o sujeito movente, que "precisa" saber de tudo - o que for possível! No nosso caso, consideramos a circulação de cartazes em Postos de Saúde: local em que é comum encontrarmos não só cartazes, mas também panfletos, banners e até leques de carnaval, com orientações à população relacionadas à saúde, por exemplo, informações sobre os tipos de insetos, sobre as diferenças sintomáticas entre gripe e dengue e, certamente, sobre a sexualidade, sobretudo a prevenção das chamadas "doenças sexualmente transmissíveis" (DST). Percebe-se, então, como o Estado responde ao que lhe seria um dever em relação a seu cidadão, posicionando-se como o que "orienta", "define", "diferencia", sempre buscando saber como a população age, sofre, vive - um saber tal que alimenta o poder, o controle sobre esta mesma população.

Em Haroche (1992) encontramos uma reflexão sobre as formas históricas de subjetivação. A partir dessa reflexão, Orlandi (2004) afirma que:

O Estado funda sua legitimidade e sua autoridade sobre o cidadão, levando-o a interiorizar a idéia de coerção ao mesmo tempo em que faz com que ele tome consciência de sua autonomia (de sua responsabilidade, portanto). (...) podemos afirmar que a submissão do homem a Deus (à letra) cede lugar à sua submissão ao Estado (às letras, ao jurídico). (p. 90).

Foucault (1988) aponta que a necessidade "de saber”, característica de nossa sociedade, está intimamente ligada às formas de poder que estruturam as relações sociais. Assim, quanto mais se sabe sobre o sexo e suas manifestações, por exemplo, mais domínio se tem. Dessa forma, como coloca Foucault (idem), saber e poder, poder e prazer são os elementos que impulsionam formas de dominação e o controle do sexo é produto dessa interação entre saber-prazer-poder. 
Daí a existência na sociedade de regras impostas à sexualidade e sua prática como forma de dominação, seja por meio do Estado, da Igreja, da medicina, da família, da pedagogia etc. Tais esferas de poder, a seus modos, impõem estratégias de dominação do sexo, multiplicando os discursos sobre este. Confessionários, consultórios, documentos obrigatórios, casamento e procriação, entre outros, trazem consigo a obrigatoriedade de se posicionar quanto à sexualidade, tornando público aquilo que é privado, íntimo, ao mesmo tempo em que se observa o desejo de falar de si e de ouvir o outro.

É a propósito de tais considerações, no que chamou de "dispositivo da sexualidade", que Foucault (idem) procurou compreender a relação discursiva entre corpo, saber e poder. Tal dispositivo se articula entre a intensidade do prazer, a necessidade de saber e a busca pelo poder sobre as manifestações da sexualidade. Assim, ao analisarmos ambos os cartazes, levamos em conta a necessidade, apontada por Foucault (1988), de que o poder tem de saber para obter/manter o poder, neste caso, o saber imposto pelo Estado sobre a sexualidade de uma parcela da sociedade. Aqui, o Estado se refere à sexualidade do sujeito travesti, significando-o como cidadão e, partindo de um saber institucionalizado por órgãos de saúde, tal instância de poder determina quem e como são seus cidadãos.

Cartaz 01: Campanha de combate à Aids

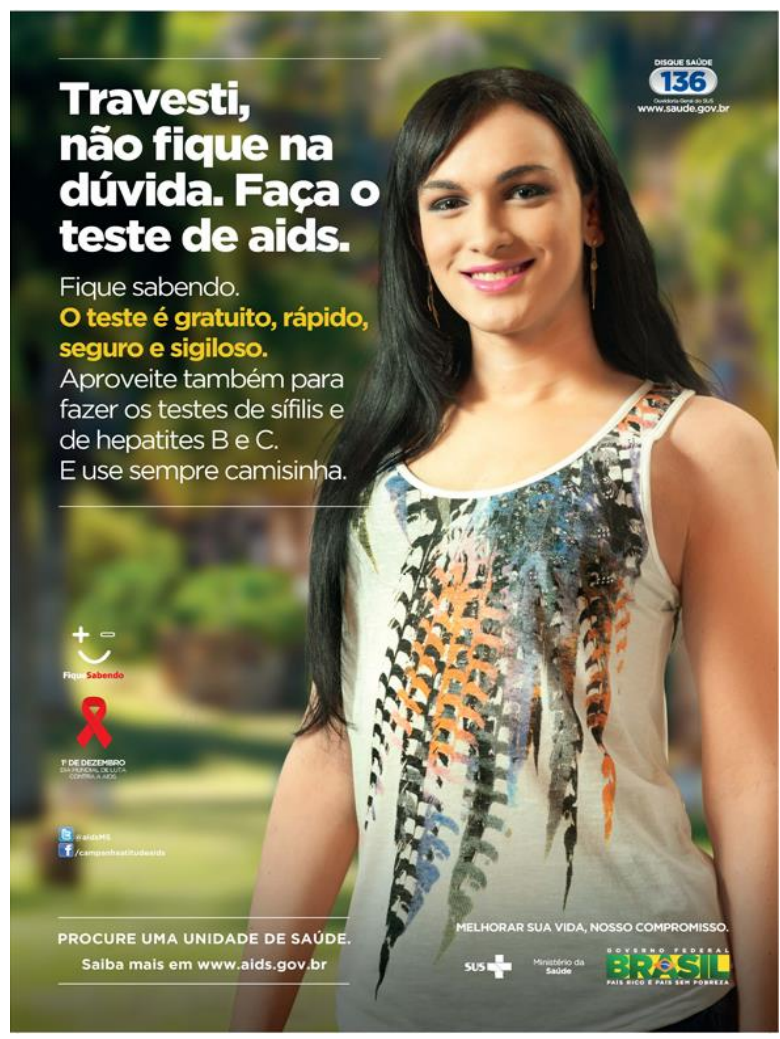




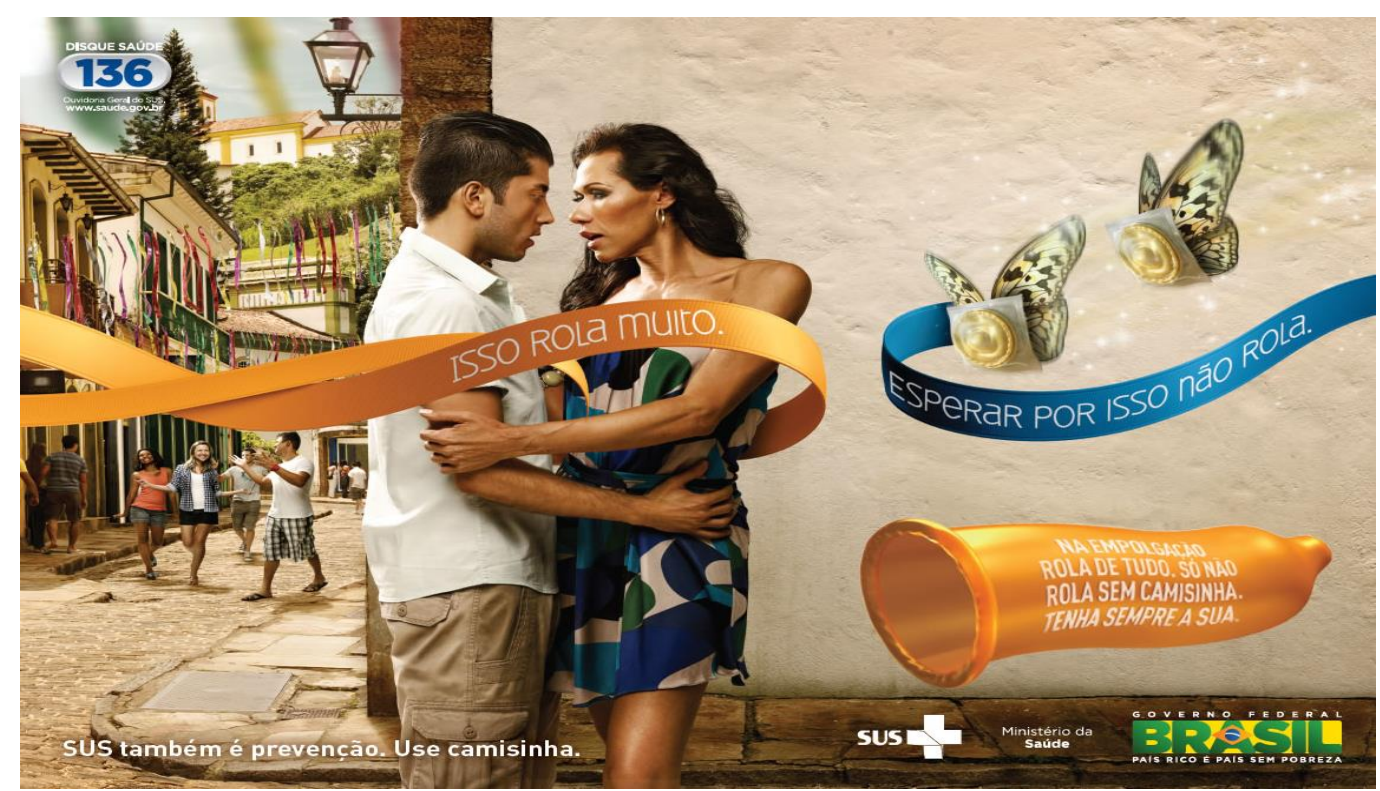

Analisando o primeiro cartaz, consideramos em A o locutor SUS (o Sistema Único de Saúde, enquanto instituição responsável pela saúde), que se dirige ao cidadão no sentido de uma política pública promovida a partir do Ministério da Saúde, como órgão que compõe o Estado no Brasil. Ou seja, é o Estado, enquanto instituição máxima de poder, que se afirma enquanto tal, através de um de seus Ministérios, de modo que podemos considerar que é o Estado que se responsabiliza por esse texto, através de suas inscrições no cartaz: "SUS", "Ministério da Saúde", "País rico é país sem pobreza".

Segundo Orlandi (2004), a posição de autoria constitui-se a partir do lugar de interpretação, definido pela relação entre interdiscurso e interlocutores. Assim, propomos dizer que, neste caso de análise, o Estado determina seu lugar de interpretação a partir da memória do dizer (interdiscurso) sanitarista, através do Ministério da Saúde, em uma relação com o seu interlocutor, a população brasileira, no geral, mas, mais especificamente, no caso do material aqui analisado, com uma parcela dessa população significada como um indivíduo "travesti”".

Vemos, então, que o Estado, assumindo a função-autor a partir da memória discursiva da saúde pública, indaga sua população e a significa, uma vez que historiciza seu discurso através da repetição, inscrevendo-se na memória do dizer. Interessante observar o que Orlandi (idem) coloca a respeito do efeito de fechamento do texto que, embora necessário, é dúbio e arbitrário (p. 76). Faz parte desse efeito de fechamento a 
imputação de autoria, que, no caso, se efetiva através dos slogans e siglas: "Brasil: país rico é país sem pobreza"; "Ministério da Saúde". Este é, pois, um efeito também imaginário, e essa unidade final (imaginária), deve ser compreendida pela filiação do dizer remetido ao interdiscurso, bem como pela relação com o contexto, elementos que determinam as possibilidades de interpretação. De modo que não há como prever, por exemplo, se a interpretação de todo cidadão brasileiro será a mesma quanto aos cartazes e nem, ao menos, que o assunto se esgote.

Pensando, agora, na outra posição-sujeito no discurso, em B, temos a quem se dirige o cartaz: à população brasileira. Mais especificamente, os cartazes analisados, partindo de uma autoria do Estado, dirigem-se ao cidadão brasileiro, uma vez que se colocam nesse âmbito, nesse espaço de interlocução, através da inscrição dessas assinaturas (siglas, slogans...) que identificam o governo brasileiro. No entanto, ocorre que, especificamente nesses cartazes, o Estado não está apenas se dirigindo ao conjunto de seus cidadãos, mas a uma parcela que é bem marcada pelo vocativo "Travesti", no primeiro cartaz, e pela imagem de um travesti, no segundo.

O que autoriza essa interlocução específica do Estado com essa parcela, entre o conjunto da sociedade civil, é justamente o discurso médico-sanitário, em que o Estado não apenas acolhe o cidadão em termos de sua saúde, mas também exerce certa vigilância. O travesti, por sua vez, está presente pela imagem que o Estado faz dele. A forma de resposta do interlocutor (B), dado o funcionamento imaginário dessa comunicação social, seria a ação deste sujeito, o travesti, de se submeter aos exames que detectam tais doenças, ou de resistir a esse submetimento.

Dadas, portanto, as condições de produção desse discurso médico-sanitário sobre o sujeito travesti no Brasil, podemos identificar o lugar social em que A e B ocupam a partir dos cartazes apresentados, além de compreendermos as relações de força funcionando, constituindo o discurso. De um lado, temos o Estado, instituição máxima de poder, se fazendo significar como tal, que "chama a atenção" publicamente de uma parcela da sociedade. De outro, temos o sujeito travesti, longe do mesmo direito à voz, como se sabe, que é convocado pelo governo através de um alerta sobre a sua saúde. Sobre a situação, observa-se o fato do Estado dirigir um "alerta" aos travestis no que tange à contaminação de doenças sexualmente transmissíveis:

A: "Travesti, não fique na dúvida. Faça o teste da aids. Fique sabendo. O teste é gratuito, rápido, seguro e sigiloso. Aproveite também para fazer os testes de sífilis e hepatites B e C. E use sempre camisinha". 
Assim, identificados os sujeitos do discurso neste caso de análise, Estado e sujeito travesti, a condição de produção dada pelo advento do cartaz em postos de saúde marca o lugar social que cada sujeito tem no discurso, bem como as relações de força.

Consideremos ainda as formações imaginárias (PÊCHEUX, idem) advindas do processo de antecipação entre A e B, neste dado discurso de análise. Assim, pensando na imagem que o Estado faz de si mesmo $\mathrm{Ia}(\mathrm{A})$, vemos que esta instituição assume a tomada de posição que por si só já a coloca em vantagem frente a qualquer discurso, justamente por ser a instituição que administra e rege sobre os direitos e deveres de cada cidadão. O Estado, então, com isso, diz saber sua importância, o valor que é atribuído às suas palavras quando este vem a público dizer. Assim, a imagem que o Estado faz vai ser produzida pela própria sociedade, historicamente, a partir da relação simbólica em que se estrutura (cidadão/Estado), concedendo a tal instituição o direito de intervir, uma vez que significa e é significada como "aquela que cuida, alerta, protege, educa - a quem todos devem obediência e respeito".

Foucault faz um paralelo entre as diferentes instâncias de poder em que se constituem simultaneamente, de um lado, um poder legislador e, de outro, o sujeito obediente: monarca/ súdito, Estado/ cidadão, pai/ criança... Esse paralelo nos instiga a perceber nos cartazes efeitos de um paternalismo zeloso: o Estado brasileiro faz aí o papel daquele que instrui seus cidadãos e, assim fazendo, mantém sua posição no poder. Nesse âmbito, a instituição parece reforçar o funcionamento do ideal paternalista, que a situa como essa entidade suprema, que pode acolher, cuidar, educar, tratar, orientar sua população, embora também possa castigar, cobrar, impor, discriminar, entre todos, os "filhos rebeldes".

Mas vamos agora discutir sobre a imagem que o Estado brasileiro faz do sujeito travesti: como o sujeito travesti está sendo significado pelo Estado que significa e, por outro lado, como o Estado se faz significar enquanto instância de poder? Como o discurso sobre o sujeito travesti está sendo significado no discurso institucional, no cotidiano a nível nacional? Dessa forma, vamos aprofundar um pouco mais do verbal e das imagens dos cartazes que constituem o nosso corpus, considerando-se os locais de veiculação e o seu público-alvo.

Pensando, então, na imagem que o Estado faz do sujeito travesti para que lhe possa falar assim, vemos que tal imagem é baseada no ponto de vista sobre o referente, a situação. Isto é, pode-se dizer que as medidas de prevenção, ou de alerta, seriam supostamente pautadas em pesquisas médico-sanitárias, em dados estatísticos e que pode- 
riam apontar um alto número de soropositivos e/ou de contaminados com diversas doenças sexualmente transmissíveis entre os que se declaram travestis. Com isso, a imagem que o Estado faz do sujeito travesti, a partir deste cartaz, indica que o vê como parte de um grupo de cidadãos "portadores" de doenças infectocontagiosas e que necessitam ser identificadas (como estratégia de contenção de uma disseminação das doenças). Isto é, justifica-se a consideração a partir do Estado de um lugar determinado, ou de uma classe de indivíduos (os travestis), que se identifica em função de elementos próprios de sua vida privada (isto é, seus hábitos sexuais...).

Temos, assim, uma interlocução específica, uma vez que este sujeito é convocado pelo Estado enquanto travesti. Veja a especificidade dessa identificação: não se trata de considerar uma faixa etária ou uma classe profissional, por exemplo, mas sim um comportamento no âmbito sexual, em que se instaura o discurso da moral.

A significação do sujeito travesti pelo Estado, então, se dá a partir da área da Saúde, que concebe o travesti como um possível portador de doenças advindas do sexo. $\mathrm{O}$ que nos leva a pensar em um indivíduo que pode ter tantas doenças sexualmente transmissíveis é o fato de ele não se preservar nas relações sexuais. O número de doenças que circunda o sujeito travesti, no cartaz, sugere ainda vários parceiros - sem proteção. Ora, quem mais ficaria na dúvida de ter ou não alguma doença sexualmente transmissível se não aqueles que têm vários parceiros e não se preservam? Temos, possivelmente, a imagem que o Estado faz do travesti: constitui grupo de risco que deve ser controlado.

Consideremos o enunciado que o cartaz traz, dividido em quatro partes:

a) “Travesti, não fique na dúvida. Faça o teste da AIDS.

b) Fique sabendo. O teste é gratuito, rápido, seguro e sigiloso.

c) Aproveite também para fazer os testes de sífilis e hepatites B e C.

d) E use sempre camisinha."

Tais dizeres sustentam-se em outros dizeres aí presentes. Como Orlandi (1988) aponta, o que não está dito (o não dito) pode ser de várias naturezas, seja, por exemplo, aquilo que sustenta o que está dito, seja o que está suposto, seja aquilo a que o que está dito se opõe ou outras maneiras diferentes de se dizer o que se disse. Nesse sentido, pensamos que esses enunciados (os ditos acima expostos) relacionam-se a não ditos tais como: 
a) O travesti tem dúvida se está contaminado com a AIDS.

b) Ele deve saber se está infectado,

c) deve estar em dia com os exames que detectam outras doenças sexualmente transmissíveis,

e, ainda,

d) deve sempre usar camisinha (ressalta-se o sempre, uma vez que em "use camisinha" já está implícito que é em todas as relações sexuais).

Tomando esses enunciados como possíveis interpretações do que está no cartaz, pensamos que o item "a" sugere que o sujeito travesti está exposto à contaminação pelo vírus HIV. De onde vem essa exposição? Pelo conhecimento que na sociedade temos sobre as formas de contágio do vírus, trata-se de um imaginário que indica um chamado "comportamento de risco", associado ou a práticas sexuais, ou ao uso de drogas injetáveis - enfim, o sujeito travesti estaria sendo identificado a ambientes e atos propícios à contaminação da AIDS. Dessa maneira, o próprio Estado condena seu cidadão a estereótipos fechados, à significação reduzida de sua sexualidade, uma vez que ser travesti, segundo o cartaz, é ter dúvida se é ou não soropositivo.

Interessante observar ainda que, mesmo que o sujeito travesti não se identifique em nada com o cartaz, o ignore, não estabeleça identificações, o cartaz é público: o alerta é para o sujeito travesti, mas está afixado em paredes das unidades de saúde do SUS em todo o país. Poderíamos, então, pensar na imagem que um sujeito heterossexual, esperando por atendimento, por exemplo, fará do sujeito travesti a partir da imagem que o Estado faz do mesmo, nesse cartaz. Não se pode subestimar o peso de um dizer sobre a saúde a partir de uma instância de Estado e, nesse sentido, é necessário reconhecer como o Estado brasileiro está disseminando (ou participando da disseminação de) uma ideia preconceituosa a respeito do travesti. A formulação de uma campanha de saúde desses/nesses cartazes sustenta-se na afirmação de que o travesti é "grupo de risco".

Se pensarmos, então, na imagem que o sujeito travesti faz de si mesmo, ao se questionar quem seria ele para que o Estado lhe falasse assim, esse alguém, segundo o Estado, seria um indivíduo possivelmente doente, que se prostitui, que não se preserva em suas relações sexuais, promíscuo, vulgar. É o Estado dizendo quem ele é e, nesse sentido, isso demanda do sujeito travesti um embate sobre a sua imagem enquanto sujeito, ele será afetado por esse discurso. Segundo Pêcheux (idem), 
(...) É claro, já de início, que o discurso que A dirige a B modifica o estado de B na medida em que B pode comparar as "antecipações" que faz de A no discurso de A. Mas por outro lado, destacamos que todo orador era um ouvinte virtual de seu próprio discurso, o que implica que o que é dito por A transforma, igualmente as condições de produção próprias a A, permitindo-lhe “continuar" seu discurso (p. 89).

Como dissemos, observando ambos os cartazes, vemos as inscrições que identificam que o dizer é de responsabilidade do Estado: "SUS", "Ministério da Saúde", "Brasil: país rico é país sem probreza". Tais inscrições demarcam um território, um espaço histórico, simbólico e geográfico institucionalizado no qual se impõe uma identificação ao sujeito enquanto seu cidadão. Aqui, o discurso do Estado está circulando, a priori, em suas "bases”, em seus próprios prédios de atendimento de saúde gratuito à população, já significados assim por um poder institucionalizado.

Dessa maneira, os cartazes e o local institucionalizados oferecem condições de produção de sentidos que se constituem e circulam pelo território nacional, que, segundo Orlandi (2011), é significado pela relação com o poder, sendo um espaço político (idem). Assim, tais cartazes nos postos de saúde lembram o sujeito travesti: eu tenho vários parceiros, eu sou grupo de risco, eu posso estar contaminado. Embora represente um saber que se origina no âmbito do científico, este saber já está em um outro lugar a partir de uma administração da Saúde Pública pelo Estado que as legitima através de sua função-autor no discurso. Podemos ver, então, que nessas condições os cartazes têm uma dimensão sócio-política articulada ao simbólico: "Estado e território estão inextricavelmente articulados na prática, têm seus aparatos e significam seus cidadãos através/com eles" (p. 20).

Como coloca Orlandi (2011), as relações entre Estado, sujeito e sociedade se produzem dadas as redes de sentidos que atravessam os dizeres, considerando-se os funcionamentos da memória discursiva e da memória institucionalizada. Assim, percebemos de que modo essa assinatura do governo, nos cartazes afixados nos postos de saúde em diversas cidades do território brasileiro, constituem o sujeito por essa territorialidade, e nela essa produção de um lugar específico enquanto classe para o sujeito travesti, que o individua enquanto cidadão através do discurso da saúde pública.

Podemos pensar ainda que, pela autoria do SUS/ Ministério de Saúde, em um braço administrativo do Estado, a imagem do sujeito travesti resulta de uma significação articulada através de uma memória institucionalizada, a partir de dados estatísticos, de índices de cidadãos infectados com doenças sexualmente transmissíveis. Essa memória, que se multiplica em outros postos de saúde, trazendo a ideia de constituição, de espaço 
uno, a que o Estado valoriza, é a que, não raro, se repete, se (re) afirma em nosso cotidiano, em debates, causas religiosas, políticas, morais etc. E, dessa forma, essa memória 'oficial' que se divulga, é reafirmada pelas outras instâncias de poder, afetando ideologicamente os sujeitos a ela submetidos, sendo responsável pela individuação do sujeito pelo Estado através da ciência médica e da estatística, produzindo-se uma continuidade entre o saber científico e a gestão de Estado.

Tal individuação ocorre, então, pelo modo como o sujeito travesti é dito, significado a nível nacional, ligando-o a uma terra e o identificando através de uma formação discursiva que lhe dá uma origem: a brasileira. Mesmo que o sujeito travesti não se identifique com a significação de si, dada pelo Estado, esse discurso faz parte e se faz presente da/na história de sua sociedade: o cartaz é o gesto de memória do Estado que, ao individuar o sujeito travesti, o faz um tipo específico de cidadão, interpelado como tal, de todo o seu domínio territorial.

Observando o primeiro cartaz, temos em letras maiores, dando destaque à mensagem principal: "Travesti, não fique na dúvida. Faça o teste da aids." Logo abaixo, continuando a mensagem, mas em letras menores, lemos: "Fique sabendo.", “Aproveite também para fazer os testes de sífilis e hepatites B e C. E use sempre camisinha”. Tais falas, provenientes de um órgão de governo, com os verbos no modo imperativo advertem, chamam a atenção do sujeito travesti e o convocam para que este encare os riscos a que se submete: "Não fique na dúvida'; "Faça o teste..."; "Aproveite"; "use sempre camisinha". Há, ainda, a exposição de argumentos, em amarelo, de modo a dar segurança ao sujeito travesti que se submeter ao exame de HIV: "O teste é gratuito, rápido, seguro e sigiloso." Temos, então, o Estado oferecendo todos os recursos possíveis para o sujeito travesti o manter informado sobre a sua sexualidade e práticas sexuais e essa menção ao "sigiloso" em que se mostra a contradição desse "cuidado de Estado", uma vez que o próprio cartaz sugere que o sujeito travesti é um possível portador de HIV.

O vocativo "travesti" indica/determina para a mensagem do cartaz um público específico - a mensagem do Ministério da Saúde é direcionada aos travestis - excluindo-se, portanto, heterossexuais, gays, lésbicas, bissexuais, transexuais etc. Em seguida a esse vocativo, temos a formulação "não fique na dúvida", em que a negativa dirigida pelo Estado, em sua interlocução com o travesti, funciona de modo a atribuir a dúvida a este sujeito. A formulação não se faz, por exemplo, através de um "se", marcando-se uma possibilidade: "se você tem dúvida, faça...". Mas com "Travesti, não fique na dúvida", o que se tem é esse sujeito sendo significado como alguém que está na dúvida se 
é portador do vírus HIV e que precisa saber se está ou não com a doença - assim como o Estado precisa saber quem são seus cidadãos soropositivos. Assim, nesse cartaz, não qualquer sujeito sexualmente ativo, mas o sujeito travesti é significado como grupo de risco, como possível aidético.

Segundo Orlandi (2011),

Essa é a contradição que lateja na maneira como os sujeitos individuados por diferentes gestos articuladores do simbólico com o político, pelo Estado, constituem o processo de identificação do sujeito na sociedade que se constituem em sua cidade, seu território, seu Estado, seu país (p. 32).

Ora, sabe-se que qualquer pessoa pode colocar-se em risco se mantiver relações sexuais com vários parceiros sem proteção e/ou compartilhar agulhas e seringas, não apenas o travesti. Mas o modo como se dá a formulação dessa campanha de saúde pública reforça, amplia e institui, assim, o preconceito, a exclusão e o fechamento do simbólico (Orlandi 2011), uma vez que o Estado delimita o sentido, significando o sujeito travesti como sujeito promíscuo. Continuando a leitura do cartaz, é atribuído ainda ao travesti ser possível portador de outras doenças sexualmente transmissíveis como sífilis e hepatites B e C. Interessante observar que a mensagem é direcionada aos travestis, mas a sua circulação é nacional, estando o cartaz afixado nas paredes dos postos de saúde para toda a comunidade.

Podemos questionar o que implica o Ministério da Saúde utilizar o vocativo "travesti": por que não usou "mulher", "homem", "gay" etc., se qualquer pessoa pode estar sujeita a contrair o vírus da AIDS? Estaria o governo significando o sujeito travesti como um sujeito que se prostitui, por exemplo? Ora, o verbal do cartaz sugere que o travesti tem vários parceiros e que nem sempre se preserva, do contrário não seria colocada a dúvida, aqui, inerente ao travesti, de possuir diversas doenças sexualmente transmissíveis.

Temos um efeito ambíguo e discriminatório: o Estado reconhece o travesti como um cidadão, mas, ao reconhecê-lo, isso se dá pelo discurso médico-sanitário. Aqui, ser travesti é, mais do que uma questão moral, uma questão de saúde pública. Tal posição do Estado, observada do cartaz, separa o sujeito travesti do conjunto de cidadãos, uma vez que o cartaz se dirige a ele, numa reação negativa e discriminatória.

Dessa forma, pode-se inferir que o Estado toma o travesti, preferivelmente, como um indivíduo que se prostitui. Estaria essa significação do sujeito travesti à prostituição relacionada a uma classe social? Um efeito de sentido advindo dessa interlocução 
específica é que os outros grupos não se prostituem ou o fazem em uma parcela muito inferior. Ou seja, a nomeação "travesti” fica discursivamente ligada à prostituição, como se fosse próprio do sujeito travesti prostituir-se, como se não houvesse travesti fora da prostituição - o que é complicado, pois é o discurso oficial que já o coloca de antemão na condição de prostituição.

Percebemos, com isso, que o Estado concebe a sexualidade do sujeito travesti ligada ao corpo enquanto matéria, como se a sua identificação sexual fosse significada com um corpo a ser vendido, comercializado. Ser travesti, aqui, é ser um sujeito que se prostitui, é ter o corpo possivelmente carregado de doenças advindas do sexo - e não um sujeito que se identifica de maneira outra com a sua sexualidade e que resiste ao modelo de sexualidade vigente.

Partindo da mesma perspectiva psicanalítica abordada por Poli (2007), Millot (1992) também considera a sexualidade de maneira desvinculada ao corpo anatômico, sendo este, para a autora, apenas um invólucro capaz de ser moldado conforme a vontade de cada um. Com compreensões nessa direção, a partir da Psicanálise, pode-se confrontar paradigmas religiosos e morais constituídos nas sociedades ocidentais, e conceder ao desejo a sua liberdade sexual. Teríamos, então, uma liberdade de significação sexual do corpo, e de práticas sexuais, como nunca antes havíamos visto.

Dessa forma, podemos perceber que ser travesti é uma questão de identificação, de desejo do sujeito que se significa e quer ser significado de forma outra. Já o fato de se prostituir advém de outros fatores (econômicos, sociais...). É raro vermos travestis assumindo cargos, frequentando faculdade, ocupando vagas no mercado de trabalho, indo à missa ou a cultos... Ao contrário, o sujeito travesti é comumente isolado, excluído, apagado do meio social. Como se sustentar economicamente se não há vagas para travestis no mercado de trabalho? Não raro, como única condição, grande parte dos travestis começa a se prostituir, uma vez que não há a possibilidade de deixar de ser aquilo que se deseja, de deixar de ser o que o identifica enquanto sujeito ao mesmo tempo em que se vive o preconceito, a não aceitação de sua sexualidade no meio social. $\mathrm{E}$, ainda, a prostituição pode ser, eventualmente, forma de resistência: é dizer à sociedade que é preferível se prostituir do que se apagar, do que se negar a viver seus desejos.

Ainda quanto à reflexão de Foucault (idem) sobre o dispositivo da sexualidade, o autor descreve um funcionamento discursivo que chamou de "relação negativa", que se constitui enquanto ferramenta do poder: trata-se do "não" ao sujeito por parte do Estado, que tem o poder de barrar, excluir e recusar. Os cartazes, assim, funcionariam dada essa 
relação negativa, conforme a análise de Foucault (idem). Uma possível interpretação do primeiro cartaz, por exemplo, diz ao cidadão: "Não transe com os travestis, pois eles podem estar contaminados com inúmeras DSTs!”; “Travestis são possíveis portadores de HIV"; "Travestis têm vários parceiros e a maioria se prostitui sem proteção" etc. Temos, aí, o "não" do Estado para aqueles que se identificam e querem ser significados em sua sexualidade de uma maneira que foge aos padrões aceitos socialmente.

A reflexão do autor, nesse sentido, contribui para analisarmos a condição do sujeito travesti nas sociedades. Buscando a liberdade sexual, conferindo sua sexualidade a nível do desejo, tem como preço a rejeição e a exclusão sociais, sendo estigmatizado: raros são os que têm empregos formais, os filhos travestis acabam expulsos do meio familiar por serem considerados uma vergonha, uma aberração que deve ser banida da vida social. Tais indivíduos acabam, assim, assumindo suas identidades à margem da sociedade e, frequentemente, se amparam na prostituição. Os cartazes mostram-se representativos desse "não" imposto pelo poder ao travesti: a recusa em se aceitar o desejo de liberdade sexual e, mais do que isso, a (re) afirmação de um discurso que discrimina, que torna público algo íntimo, privado do sujeito.

Fazendo um paralelo, semelhantemente ao que ocorre hoje com os travestis, no passado diversas mulheres que perderam a virgindade antes do casamento ficaram relegadas a casas de tolerância, bordéis, zonas. Se hoje a realidade da mulher é já outra, a do travesti permanece a da marginalização, uma vez que o Estado mesmo reforça essa condição e o discrimina como sujeito portador de doenças sexualmente transmissíveis.

Notemos, agora, o efeito "promocional" que o cartaz sugere no que se refere ao verbal: "o Teste é gratuito, rápido, seguro e sigiloso." - essas especificidades do teste são tudo o que um sujeito contemporâneo busca em um único produto: não precisar gastar dinheiro; agilidade no serviço; segurança quanto ao resultado e privacidade. Em seguida a esses argumentos que buscam convencer o sujeito travesti, temos "Aproveite também para fazer os testes de sífilis e hepatite B e C". O termo "aproveite também para" sugere uma oferta, um bônus, algo promocional, como se estivesse sendo tratado de algo simples, banal. Além disso, ainda temos como discurso de propaganda a imagem de uma modelo feliz e segura, sugerindo o resultado: "Fique feliz como eu".

Em se tratando da foto do primeiro cartaz, acompanhando o texto escrito, temos, como se vê, uma imagem idealizada de um travesti. Sabe-se que, para atingir um ideal de feminilidade como o exposto no cartaz, são necessários inúmeros recursos que, nem sempre, a maioria dos travestis têm acesso. Indo mais além, a imagem que temos se 
assemelha mais a um transexual do que a um travesti propriamente dito. $\mathrm{O}$ sujeito travesti, em nossa leitura, se caracteriza e se identifica com o excesso dos grandes centros urbanos e seu corpo carrega as marcas dessa identificação. Cores variadas nos cabelos, muita maquiagem, roupas curtas que misturam diversas texturas, bijuterias que se destacam, salto plataforma, entre outros artefatos "tidos" como pertencentes ao universo feminino, que são usados, em geral, em abundância pelos travestis.

Talvez a imagem de um travesti mais real "agredisse" aos olhos da comunidade conservadora que não aceita e discrimina os travestis. Ou talvez, ainda, mostre-se uma "preocupação" em retratar o travesti no cartaz, como se o mesmo, através de um modelo, estivesse sendo bem significado (?). De qualquer forma, a imagem que encontramos no cartaz, comparadamente às imagens de travestis que encontramos on line, por exemplo, pode nos indicar uma censura: algo dele fica de fora para que o travesti entre na publicidade da Saúde Pública. Notamos, pois, além da exclusão e marginalização, a imposição de um ideal de imagem pública: na possibilidade de se significar o travesti enquanto cidadão, apaga-se, silencia-se na sua apresentação aquilo que "agride" aos olhos da sociedade burguesa. No caso, são apagadas marcas de sensualidade, o exagero, o extravagante, o erótico etc., em prol de uma "aparência aceitável" para que o Estado possa significar o sujeito travesti como parte da população.

Note-se que o sujeito travesti, significado no primeiro cartaz, está sorrindo, aparentemente feliz e saudável, o que contrasta com o verbal, pois esse travesti não parece estar com dúvida, nem doente, ao contrário, parece estar seguro e gozando de plena saúde. Então, a dúvida seria para quem? Para o travesti ou para quem lê? Esta mensagem estaria funcionando como um aviso, uma advertência ao "usuário" do corpo do travesti? Podemos pensar em outra paráfrase possível:

"Travesti, não fiquei na dúvida."

$$
\rightarrow \text { "Perigo! Você pode se contaminar." }
$$

Temos, então, uma rarefação de sentidos, uma vez que só sobra a ideia do sujeito travesti constituído pelo sexo perigoso, deixando de significar tudo para significar "isso".

Quanto ao segundo cartaz, a imagem fotográfica nos mostra, mais à esquerda, uma rua enfeitada para o carnaval, pessoas descontraídas e um certo movimento. Com um olhar mais atento, percebemos que a festa acontece em uma cidade histórica, casas 
no estilo colonial, ruas de pedra e, ao fundo, uma igreja barroca. No centro da imagem, temos um casal composto por um homem e um travesti. Note-se que o casal não está na rua onde a festa se dá, mas virando uma esquina, afastado dos olhos das pessoas - e até mesmo do olhar divino!

Com essa imagem, formulamos as seguintes questões para reflexão: Por que não estaria o casal em meio às outras pessoas? Ou o casal estaria se escondendo? Ou, simplesmente, haveria a necessidade de um distanciamento para um contato mais privado, íntimo? Podemos perceber que, em um dos sentidos possíveis, há uma discriminação sexual, uma vez que este casal só se formaria escondido e para fins sexuais.

Abaixo, do lado direito, temos um preservativo que sugere uma seta, uma indicação, um caminho oposto ao da festa e que diz: "Na empolgação rola de tudo". Podemos interpretar que o Ministério da Saúde se coloca aí como uma instituição que "sabe" que, durante o carnaval, é comum travestis praticarem relação sexual na rua. Percebe-se que é possível se esconder do olhar do povo, até mesmo do olhar de Deus, mas não se escapa dos olhos do Estado.

Ainda, a camisinha aberta e em formato de uso, sugere que tudo pode acontecer nas vielas próximas aos blocos de carnaval. Outros preservativos sobrevoam a camisinha aberta com o dizer: "Esperar por isso não rola": aqui, em se tratando de travesti, o excesso de proteção nunca é o bastante. Além disso, as expressões de ambos, se olhando abraçados, são de desejo; a serpentina que os envolve, lançando-os ao se cruzar sugere uma união - tais elementos, juntos, reforçam ainda mais um discurso de que o sexo pode acontecer ali mesmo, na rua.

Segundo Orlandi (2012),

\begin{abstract}
Relacionando sujeito/corpo/linguagem/sociedade, visamos compreender como o corpo, pensando-se na materialidade do sujeito, sua historicidade, é significado em um ou outro espaço de existência, considerando que o espaço significa. Como se constituem seus processos de significação (interpelação, individuação e identificação) concebendo os homens como seres simbólicos e histórico-sociais, pensando-se o interdiscurso e sua relação ao espaço (p. 87).
\end{abstract}

Aliando a imagem do casal ao verbal, temos, na serpentina que os envolve, o seguinte dizer: "Isso rola muito". Levando em conta a função dêitica do pronome demonstrativo "isso", a sua interpretação sugere a referência ao fato de homens se relacionarem com travestis - no Carnaval, quando rola de tudo! Mas no que se refere ao seu funcionamento, o sentido específico para "isso", não é completo pela imagem, pois o leitor tem que fazer a relação necessária entre essa imagem (um casal) e a que o pronome "is- 
so" pode remeter: sexo. Embora a imagem não seja um casal fazendo sexo, na imagem associam-se a camisinha, um casal empolgado, um travesti... Então, ocorre que ao invés de o cartaz estar dizendo "Sexo rola muito no carnaval", ele está dizendo "Sexo (com travesti) rola muito no carnaval". Assim, vemos que a imagem não diz "sexo", mas especifica esse "sexo" que é o objeto ao qual o leitor terá que pensar para completar o enunciado.

Aqui, percebemos que o governo diz saber o que acontece à margem, fora de seu controle, como se fosse onipresente e vigiasse a todos, até mesmo àqueles que frequentam vielas, becos e esquinas. Essa frase sugere que o Estado admite e não omite a relação sexual entre homens e travestis, mas essa relação sexual é significada de forma engessada, como se o sexo entre um homem e um travesti só ocorresse assim: longe dos olhos, mas na rua; na empolgação de uma festa como o carnaval, sem compromisso ou sentimento. Mais uma vez, temos o sujeito travesti significado como um sujeito intimamente ligado à prática sexual, individuando-o, assim, como vulgar, grupo de risco, um corpo alterado com finalidade de ser "vendido".

Vemos, então, que o que autoriza o Estado a falar com o cidadão enquanto tal é o lugar da Saúde Pública e é a partir deste lugar que o sujeito travesti é significado e individuado por essa instância de poder. Com isso, podemos considerar ambos os cartazes como um recorte enunciativo que reforça o estereótipo há muito repetido sobre o sujeito travesti e que funciona, segundo Orlandi (idem), como um "lembrete" de memória: "ou seja, são textualidades que, produzidas, desengatilham um mecanismo da memória de arquivo (institucionalizada, portanto) que nos faz entrar no uníssono de um sentido petrificado, eternalizado" (p. 18). Aqui, trata-se de conceber o sujeito travesti como promíscuo, possivelmente infectado, grupo de risco.

Procuramos, assim, analisar a individuação do sujeito travesti pelo Estado, órgão máximo de poder, bem como o processo de significação e identificação a que está sujeito a partir da formação discursiva governamental. O Estado, através de instâncias de controle à saúde pública, está institucionalizando uma imagem preconceituosa do travesti, que estaria sendo legitimada por estudos estatísticos.

A partir de uma memória institucionalizada, produzida e gerenciada através dessas instâncias de Estado, o sujeito travesti fica significado como um sujeito promíscuo, que possivelmente se prostitui, que não se preserva e por isso tem dúvida se possui as doenças infecto contagiosas advindas das relações sexuais. A sexualidade do sujeito 
travesti, através de ambos os cartazes, é trazida a público, significada como uma questão médico-sanitária e diretamente associada à prostituição, ao sexo sem compromisso, causando uma exposição do sujeito e o fechamento de sentidos sobre sua significação.

É importante ressaltar que os sentidos não se fecham e que outras interpretações possíveis sobre tais cartazes podem ser realizadas. O que nos interessa, de fato, é possibilitar a abertura do simbólico constituído, fortalecendo, então, a busca por sentidos outros. Assim, como trabalho do analista, nos compete de-superficializar o texto para se chegar ao processo discursivo. Na superfície de uma leitura comum, o Estado estaria "cumprindo seu papel", "reconhecendo" o sujeito travesti como cidadão partícipe da sociedade. O que ocorre, para o analista, é como se dá esse reconhecimento que não escapa a certas determinações.

\section{Referências Bibliográficas:}

FOUCAULT, Michel. 1988. A história da sexualidade I: a vontade de saber. Rio de Janeiro: Ediçõos Graal.

HAROCHE, Claudine. 1992. Fazer dizer, querer dizer. Ed. Hucitec, São Paulo. MILLOT, Catherine. 1992. Extrasexo: ensaio sobre o transexualismo. São Paulo: Escuta.

ORLANDI, Eni P. 2011. Os sentidos de uma Estátua: Fernão Dias, individuação e identidade Pousoalgrense. (Pág. 13-34) In: Discurso, espaço, memória - caminhos da identidade no Sul de Minas. ORLANDI, Eni Puccinelli (Org.): Campinas, Editora RG. $160 \mathrm{p}$.

2012. Processos de significação, corpo e sujeito. In Discurso em

Análise: sujeito, sentido, ideologia. Campinas, SP. Ed. Pontes. p. 83-96.

bólico. Campinas. Ed. Pontes.156p 2004. Interpretação; Autoria, leitura e efeitos do trabalho sim. 2004. Cidade dos Sentidos. Campinas, São Paulo: Ed. Pontes. P. 159.

da Unicamp, 1988.

Discurso e leitura. São Paulo/ Campinas: Cortez Editores/ Editora PÊCHEUX, M. 2010. Análise automática do discurso (AAD-69). In Por uma análise automática do discurso. Uma introdução à obra de Michel Pêcheux. GADET, F. e HAK, T. (Org.), Campinas: Ed. UNICAMP. p. 61-161.

POLI, Maria Cristina. 2007 Feminino/Masculino. Rio de Janeiro. Ed. Jorge Zahar. $76 \mathrm{p}$. 

Para citar essa obra:

PEREIRA, L. N., SILVA, T. D. Sentidos (tra)vestidos: a individuação e a constituição do sujeito travesti pelo Estado In: RUA [online]. n. 21. Volume 2, p. $321-339$. ISSN 1413-2109. Junho/2015. Consultada no Portal Labeurb - Revista do Laboratório de Estudos Urbanos do Núcleo de Desenvolvimento da Criatividade.

http://www.labeurb.unicamp.br/rua/

Capa: Foto da autora. Visão geral da Rua Dias Ferreira.

\section{Laboratório de Estudos Urbanos - LABEURB}

Núcleo de Desenvolvimento da Criatividade - NUDECRI

Universidade Estadual de Campinas - UNICAMP

http://www.labeurb.unicamp.br/

Endereço:

LABEURB - LABORATÓRIO DE ESTUDOS URBANOS

UNICAMP/COCEN / NUDECRI

CAIXA POSTAL 6166

Campinas/SP - Brasil

CEP 13083-892

Fone/ Fax: (19) 3521-7900

Contato: http://www.labeurb.unicamp.br/contato 